\title{
Présentation de Wilhelm Genazino
}

\section{Wolfram Nitsch}

\section{OpenEdition}

\section{Journals}

Édition électronique

URL : http://journals.openedition.org/ccs/577

DOI : $10.4000 / \operatorname{ccs} 577$

ISSN : 2558-782X

\section{Éditeur :}

Presses universitaires de Rennes, Association des lecteurs de Claude Simon

\section{Édition imprimée}

Date de publication : 30 avril 2007

Pagination : 137-140

ISBN : 9782354120122

ISSN : 1774-9425

Référence électronique

Wolfram Nitsch, «Présentation de Wilhelm Genazino », Cahiers Claude Simon [En ligne], 3 | 2007, mis en ligne le 21 septembre 2017, consulté le 15 septembre 2020. URL : http://journals.openedition.org/ $\operatorname{ccs} / 577$ 
Paroles d'écrivains 

Wilhelm Genazino, né en 1943 à Mannheim, est l'un des grands stylistes du roman allemand contemporain. D'abord journaliste libre, puis rédacteur de journal et de revue ainsi qu'auteur de pièces radiophoniques, il attira l'attention de la critique par sa première œuvre romanesque, la trilogie «Abschaffel» (1977-1979), qui met en lumière la vie intérieure d'un petit employé solitaire. Depuis, il a publié une douzaine de romans dont les protagonistes sont souvent des nomades urbains, des vagabonds discrets et lucides qui observent la vie quotidienne dans la société de consommation. Parmi ses fictions plus récentes, on a célébré en particulier Die Kassiererinnen (Les Caissières, 1998), Lin Regenschirm fur diesen Tag (Un parapluie pourcejour-là, 2001) et EineLrau, eine Wohnung, ein Roman (Une femme, un appartement, un roman, 2003), dont les deux dernières ont été traduites en français. En 2004, il obtint le prestigieux prix Georg Biichner; en 2007, le prix Kleist. Comme le romancier Genazino est en même temps un grand lecteur de romans, il a écrit quelques essais critiques remarquables, notamment sur les rapports entre la littérature moderne et la photographie. Dans Das Bild des Autors ist der Roman des Lesers (L'image de l'auteur est le roman du lecteur, 1994), il s'interroge sur le rôle des photos d'auteurs ; dans Ans der Ferne (De loin, 1993), il commente de vieilles cartes postales, marchant en quelque sorte sur les traces du narrateur d'Histoire. Il n'est donc pas surprenant que dans ses essais critiques il cite parfois les romans de Claude Simon, en particulier La Corde raide qui, grâce à une traduction parue en 1964 et toujours disponible, a sans doute trouvé plus de lecteurs en Allemagne qu'en France. Dans Achtung Baustelle 
(Ralentirtravaux, 1998), il examine scrupuleusement une seule phrase de ce texte d'après-guerre, soulignant le « travail de traduction de la métaphore » qui s'y reflète comme dans un miroir ardent : « Si vous restez suffisamment de temps assis à regarder, deux ou trois heures par exemple, vous voyez la mort» (p. 176). Et ce sont quelques paragraphes du même texte (p. 65, 73, 169-170) qui constituent le point de départ de l'essai suivant, publié en 1999 dans la revue suisse $D u$ et repris dans le recueil Dergedehnte Blick (Le Regardprolongé, 2004).

Wolfram NITSCH 